\title{
The climate challenge for the energy system
}

\author{
Angela Köppl · Karl W. Steininger
}

Published online: 8 March 2012

(C) Springer Science+Business Media New York 2012

If dangerous and irreversible climatic events are to be avoided, global average temperature should not increase by more than $2{ }^{\circ} \mathrm{C}$ above pre-industrial levels (European Parliament and the Council 2009). Meinshausen et al. (2009) show that in order to achieve such a global target, a mitigation pathway has to limit global emissions to about $70 \%$ below 1990 levels by 2050. There is thus a clear need for immediate binding commitments on greenhouse gas emission reductions in the postKyoto period. While the Copenhagen accord (affirmed by COP 16 in Cancun) recognized the need for deep cuts in emissions, within the UNFCCC framework (UNFCCC 2009, 2010), it has so proved impossible to obtain agreement on binding commitments with respect to quantification of reduction levels.

The lack of global consensus did not deter the EU from acting alone. In an effort to establish binding commitments to emission reduction, the EU introduced a "climate and energy package" at the end of 2008 (European Commission 2008). The new legislation obliges Austria and other EU member states to implement several policy changes. Thus:

- The "EU climate and energy package" agreed upon in December 2008 by the Council and the EU parliament stipulates the implementation of comprehensive energy and climate goals for 2020. At the overall EU level, greenhouse gas emissions are to be reduced by $20 \%$ below the 1990 level, the share of renewables in final energy demand is to be raised to $20 \%$, and energy efficiency is to increase by $20 \%$ (this latter point may be viewed as redundant once the other two goals are reached). The specific goals for Austria stipulate an increase

\footnotetext{
A. Köppl ( ()

Austrian Institute of Economic Research, Arsenal Objekt 20, 1030 Vienna, Austria e-mail: Angela.Koeppl@wifo.ac.at

K. W. Steininger

Department of Economics and Wegener Center for Climate and Global Change, University of Graz, Universitaetsstr. 15, 8010 Graz, Austria
} 
in the share of renewable energy in final energy demand to 34\% by 2020 (with respect to the reference year of 2005, the Austrian share of renewables was already well above the EU average) and a reduction of GHG emissions in sectors not covered by the EU emissions trading system (EU ETS) of $16 \%$ compared to 2005 emission levels. The overall EU goal for installations covered by the EU ETS is an emission reduction of $21 \%$, compared to 2005 levels.

- Discussions on long term energy and climate goals up to 2050 started within the EU. In order to limit global temperature rise to $2^{\circ} \mathrm{C}$, compared to the preindustrial level, the EU acknowledges that EU greenhouse gas emissions need to be reduced by 80-95\% below 1990 levels by 2050 (European Council, 2009). In March 2011 the European Commission published "A Roadmap for moving to a competitive low-carbon economy in 2050" (European Commission 2011). This maps out how such long term low carbon strategies are to be achieved. The achievement of consensus on the EU energy and climate package, and long-term strategy was not only motivated by climate change issues but also by the prevailing relatively high EU dependency on energy imports from regions characterised by political instability. The only way out of this dependency is an increase in energy productivity linked with a stronger focus on renewable energy.

Let us now focus on Austria. With respect to the Kyoto Protocol, although Austria was willing to adopt relatively ambitious targets, it has so far proved unable to meet its obligations. For the 2008-2012 Kyoto period Austria has targeted a reduction of GHG emissions of $13 \%$ below the 1990 emission level. If emission reductions are not achieved domestically, Austria has to buy emission rights from abroad, as generated by the Kyoto-instruments of Joint Implementation (JI) or the Clean Development Mechanism (CDM). The Austrian JI/CDM program has a budgetary endowment of 530 million euros, sufficient to cover the acquisition of JI/CDM certificates equivalent to 45 million tonnes of $\mathrm{CO}_{2} \mathrm{e}$ for the Kyoto period 2008-2012. As this amount of emission certificates will not be sufficient to cover the Kyoto gap further budgetary means need to be provided for.

In order to meet the subsequent, post-2012 EU objective, i.e. the EU 2020 targets, the Austrian Climate Act was passed in November 2011. This provides the basis for emission reductions for those sectors not covered by the EU Emission Trading Scheme.

While the EU 2020 objectives are ambitious and well-defined, they also need to be accompanied by a more comprehensive analysis of energy systems in their totality. Such an analysis is provided in detail for the national level by Köppl et al. (2011), and for the sub-national level (i.e. including regional and stakeholder perspectives) by Wolkinger et al. (2012) In building on this research we are able to describe the challenges facing energy systems in terms of the following brief points:

- A radically new perspective concerning the energy system is required

The overall target of limiting global warming to an increase of no more than $2{ }^{\circ} \mathrm{C}$ cannot be reached by merely following a business as usual path and making minor technological changes. Immediate substantial restructuring of the energy system is 
needed. This calls for much broader diffusion of available alternatives, together with a simultaneous increase in $R \& D$.

Standard analyses of the energy system typically have their main focus on the availability of primary energy sources and energy generation. Such a perspective makes it easy to overlook significant changes at other levels of the energy system. Clearly, problems related to path dependencies across the energy cascade can only be overcome by adopting a more holistic or integrated point of view. In this respect, it appears that perspectives in which the end of the energy cascade, i.e. energy services, are made the starting point of analysis may be particularly fruitful. A focus on energy services is crucial for gaining a true understanding of the energy system. The provision of energy services such as adequate room heating, or access to people and goods, etc. is much more relevant in terms of welfare than mere quantification of energy consumed.

- Linkages need to be described between energy services, the role of new materials and technologies, and their impact on "technology wedges"

The two studies EnergyTransition (Köppl et al. 2011), a national level analysis, and ClimReg (Wolkinger et al. 2012; Steininger et al. 2012), a regional analysis, both describe concrete applications of a new, "energy service based" philosophy. From the energy service perspective three economic sectors are of central importance: mobility, buildings, industry. Energy services can be provided by a broad range of technologies. In Köppl et al. (2011) technology options are developed for the national level using storylines to designate specific reduction potential in the form of "technology wedges" up to 2020. Each technology wedge is defined as an option to reduce Austrian $\mathrm{CO}_{2}$ emissions by a certain amount by 2020 . Following a common methodology, technology wedges were developed in a bottom up approach for the areas mobility, buildings, industry, and electricity and heat supply. The role of new materials is explicitly addressed in the areas buildings and mobility. The result is a catalogue of technology wedges that can be used in order to meet the Austrian GHG reduction targets as defined by the EU Energy and Climate Package. Using two real cases of climate action plan development, Wolkinger et al. (2012) describe how the process of stakeholder involvement needs to be carried out in order to develop such wedges, when broad political acceptance is sought for unambiguous and successful implementation.

- The need for a comprehensive policy approach in meeting 2020 targets

The analyses of technological options and those of the reduction requirements resulting from a reference scenario and the policy objectives, show that the implementation of a comprehensive bundle of measures is necessary in order to fulfil the Austrian energy and climate targets. In addition to devising a multitude of specific targets for the different levels of the energy system and for the various individual sectors, immediate implementation of emission reduction measures is also essential. In this respect, the deployment of energy efficiency options is considered preferable to the adoption of low carbon technologies as the former reduce both emissions and energy flows simultaneously. The challenge in both 
cases, however, is to find technology options that do not lead to technological lockins. This means that the horizon beyond 2020 needs to be kept in mind. In addition, in attempting to identify policy options for emission reduction, one needs to be aware of possible inconsistencies arising with respect to quantification methods. For example, the options "house insulation" and "heating system fuel switch" each have an individual emission reduction potential. However, when both options are to be chosen, double counting has to be avoided. We suggest quantifying emission reduction in a specified order, e.g. first exploit insulation, and apply the fuel switch option only to the heating demand remaining after insulation.

- The need to consider economic impact in both the investment and in the operating phase

The restructuring of the energy system requires considerable investment. Investment in the transformation of the energy system translates into an economic stimulus with corresponding output and employment effects. Taking the example of a so-called energy efficiency portfolio, which comprises two dozen wedges from each of the above areas (building, mobility, manufacturing, energy supply), Köppl et al. (2011) valued the demand for additional investment at 6.3 billion euros p.a. (on average for the period 2009-2020). Within a static input-output framework this investment triggers an average p.a. output effect of roughly 9.5 billion euros and value added of 4.6 billion euros. The implementation of such an energy efficiency portfolio results in the creation overall of some 80,000 jobs (or 76,000 full time equivalents).

While the stimulus effect of investment relates only to the transformation period of the energy system, cost savings in the operating phase prevail over the whole service life of the technology. In general, technology wedges realise operating cost savings. However, simple comparison between technology wedges with respect to cost savings and investment needs within particular years or particular pre-defined periods, is not particularly helpful as it overlooks the fact that the actual capital costs of each technology wedge are dependent on a variety of parameters such as the service life of the technologies. Thus, for any such economic analysis to be meaningful, factors such as assumed discount rates or projected fossil fuel price developments need to be a crucial part of the analysis.

- The central role played by the building sector

The great challenge for the building sector lies in the need to extend both the scope and speed of high quality refurbishment of the existing building stock. This has proved to be an elusive goal to date. Improving the thermal efficiency of the building stock of the post-war period needs to be given the highest priority. A highly important aspect here is the need to influence user behaviour by raising overall energy awareness. This also has to go hand in hand with a significant (technical) reduction of the energy need for buildings. Future buildings will be characterized by nearly zero energy consumption or by their ability to generate excess energy. This will contribute to an increasingly decentralised energy supply.

- The need to consider the policy framework 
While for the most part decision makers acknowledge the existence of climate targets, practical implementation of target goals is often pushed aside as a result of various political and institutional barriers. For example, insufficient knowledge concerning the potential for or impact of emission reduction may result in various forms of stakeholder resistance, as may a focus on specific rather than systemic impact when formulating policy design. A framework focusing on energy services as starting point, as outlined here, offers several advantages: (1) all relevant reduction options in different sectors are considered and quantified, (2) interferences between different options within and across sectors are considered, (3) changes in energy demand due to reduction options are balanced with energy supply, and thus take the entire energy system into account, and (4) reduction options are considered at each step of the energy cascade, beginning with energy services. Reduction options starting at this step of the energy cascade are the most effective. Making the surrounding framework an integral part of the analysis guarantees more efficient scheduling and assessment of policy measures for decision makers. This increases the possibility that climate policy targets will be met. Political acceptance of new measures is also likely to be much higher when stakeholders are involved early on in the decision making process. In practice it has often proved helpful to aim first at gaining agreement among all stakeholders on the "target state of the world" (e.g. refurbishment rate, public transport share, etc.), and only thereafter to engage in discussion concerning the particular measures needed to get there (see Wolkinger et al. 2012). Such a quantitative framework also supplies an excellent basis for subsequent monitoring with respect to the targets set.

- The need to consider the long term and the impact of technological lock-in

The 2020 emission reduction targets serve as an intermediate step towards the longer term perspective of de-carbonising the economy in order to limit global temperature rise to $2^{\circ} \mathrm{C}$. When implementing measures for the required transition it is essential to keep this long term perspective in mind in order to avoid the creation of adverse lock-in effects with respect to technologies, associated infrastructure, social behaviour and institutions.

The articles of this special issue cover aspects from the different domains that the climate challenge raises for the energy system. Grossmann et al. analyze the one renewable energy technology, photovoltaics, that is given by far highest potential, both in technological terms, and economic terms. The authors analyze the possibility of a practically full shift of the global energy system to photovoltaic supply by 2050 , and the economic implications thereof. They find that it is possible in economic terms, even though current supply from PV is still below $0.1 \%$. BednarFriedl analyses in a stylized two-country intertemporal general equilibrium model welfare maximizing emission caps in emerging and industrialized countries, taking account of country differences in technology, environmental preferences and saving rates. Simultaneous target setting is compared to a sequential one in which the 
industrialized country commits itself to binding targets first. One key finding is that an industrialized country like the EU might be willing to choose a more stringent emission target as a first mover. This is contrary to first thought that a unilateral policy is always 'symbolic'. Rather, this sequential approach is welfare superior for both industrialized and emerging countries. Brauneis et al. analyze the question whether a price cap in emission permit systems - discussed to ease introduction and limit industry opposition to such systems-does change the incentive structure for firms in technological choice. They find that the lower the cap, the more investment is driven away from clean technologies, but that a range of technological factors determine the specific implications. Bednar-Friedl et al. explore in a general equilibrium model setting policy measures suitable to alleviate potential losses in international competitiveness for Austria due to carbon leakage that might result from stringent EU climate policy. By comparing different concessions to energyintensive trade exposed sectors, they find that grandfathering of emissions allowances is less cost effective to reduce leakage than export rebates and output subsidies. Finally, Steininger et al. analyze one specific measure in the transport sector, an expansion of the heavy duty vehicle charge from the primary road network to also the secondary road network, as currently discussed in many European countries. They find that such an instrument is environmentally effective, but needs to be accompanied by complementary measures to avoid detrimental implications for peripheral regions, which are in general more dependent on the secondary road network, in terms of distributional fairness.

\section{References}

European Commission (2008) Communication from the Commission to the European Parliament, the Council, the European Economic and Social Committee and the Committee of the Region, "20 20 by 2020. Europe's climate change opportunity", COM 2008/30 final

European Commission (2011) Communication from the Commission to the European Parliament, the Council, the European Economic and Social Committee and the Committee of the Regions, a roadmap for moving to a competitive low carbon economy in 2050. COM (2011) 112 final

European Parliament and the Council (2009) Decision No 406/2009/EC of the European Parliament and of the Council of 23 April 2009 on the effort of Member States to reduce their greenhouse gas emissions to meet the Community's greenhouse gas emission reduction commitments up to 2020, Brussels

Köppl A, Kettner C, Kletzan-Slamanig D, Schleicher S, Schnitzer H, Titz M, Damm A, Steininger K, Wolkinger B, Lang R, Wallner G, Karner A, Artner H (2011) EnergyTransition 2012/2020/2050. Strategies for the transition to low energy and low emission structures, commissioned by the Austrian "Klima- und Energiefonds", Vienna, 2011. http://energytransition.wifo.ac.at

Meinshausen M, Meinshausen N, Hare W, Raper SCB, Frieler K, Knutti R, Frame DJ, Allen M (2009) Greenhouse gas emission targets for limiting global warming to $2^{\circ} \mathrm{C}$. Nature. doi:10.1038/nature 08017

Steininger K, Amon B, Damm A, Grossmann W, Heimrath R, Hörtenhuber S, Kurzmann R, Lauer M, Prettenthaler F, Steiner D, Tatzber F, Wolkinger B (2012) ClimReg-Bundeslandspezifische Technologieszenarien als Entscheidungsgrundlage für eine zukunftsfähige Energienutzung. Final report, Vienna

UNFCCC (2009) Report of the conference of the parties on its fifteenth session, held in Copenhagen from 7 to 19 December 2009, Distr. GENERAL FCCC/CP/2009/11/Add.1, 30 March 2010 
UNFCCC (2010) Draft decision/CP.16 outcome of the work of the Ad Hoc Working Group on long-term Cooperative Action under the Convention. http://unfccc.int/files/meetings/cop_16/application/pdf/ cop16_lca.pdf

Wolkinger B, Steininger KW, Damm A, Schleicher S, Grossmann W, Türk A, Tatzber F, Steiner D (2012) Implementing Europe's climate targets at the regional level. Clim Policy. doi: 10.1080/14693062.2012.669096 